\title{
Postnatal weight and behavior changes as a function of components of prenatal maternal injection procedures'
}

RONALD L. WEBSTER

HOLLINS COLLEGE

The experiment evaluated postnatal weight and behavior effects which resulted from components of prenatally administered subcutaneous injections. Pregnant Ss received handling, hypodermic needle insertions, or distilled water injections in one of three trimesters of gestation. Differences in maze learning in offspring were related to differences in weight lost during the experiment. It appeared that differential resistance to conditions of food deprivation served to contaminate the learning data. It was concluded that several previous studies which involved prenatal maternal treatments with various tranquilizers reported learning data which may share in the confounding of resistance to deprivation conditions with maze learning measures.

Several conflicting reports appear in the literature regarding the effects of prenatal maternal treatments with tranquilizing drugs upon postnatal behavior of offspring. Werboff \& Kesner (1963) reported that learning was poorer in the offspring of rats injected with meprobamate or reserpine during gestation than in the offspring of control rats who received distilled water. These investigators reported no behavioral effects as a function of the stages of pregnancy during which Ss were treated. Hoffeld \& Webster (1965) indicated that the postnatal behavioral effects of prenatal maternal injections of tranquilizers were related to the trimester of gestation in which Ss were treated. Offspring of Ss in all groups treated during the second trimester were inferior in maze learning when compared with offspring of Ss treated in the other trimesters. An interesting finding of the Hoffeld and Webster experiment was that even the offspring of Ss injected with distilled water during the second trimester were inferior in maze learning when compared with Ss treated similarly in the other trimesters. The divergence of the second trimester controls suggested that any drug effects in this period may have been confounded with stress effects resulting from the injection procedures.

Stressful effects induced in offspring by components of prenatal maternal injection procedures were evaluated in the present study. Support for this approach to the problem was found in a report by Thompson \& Goldenberg (1962) which showed maternal response to stress induced in the second trimester of gestation was greater than that shown in the other trimesters. Subjects

Sprague-Dawley rats were received from the supplier, Dublin Laboratory Animals, on day 2 of gesta- tion. The 63 animals were randomly assigned to one of nine treatment groups. These animals provided 216 offspring (representing all groups) for use in this study. Apparatus

A straight alley was used for initial training trials, and a Lashley type-III maze was used to provide the major behavioral test. Apparatus details have been described elsewhere (Hoffeld \& Webster, 1965).

\section{Procedure}

The experiment employed 18 groups of $\mathrm{Ss}$ in a 3 by 3 by 2 factorial design. One independent variable consisted of treatments administered to gravid females: distilled water injections, hypodermic needle insertions, and handling. The second major independent variable was the administration of treatments in early, mid-, or late pregnancy. The remaining independent variable was the sex of the offspring. There were 12 Ss in each of the 18 cells of the design.

During four successive days in I early (days 5-8), II mid- (days 11-14), or III late (days 17-20) pregnancy each female was given one of the three treatments at $8 \mathrm{hr}$. intervals. Injections were subcutaneous dorsal. Water treated Ss (W) were injected with distilled water, $2 \mathrm{cc} / \mathrm{kg}$. Needle treated Ss (N) received the insertion of a hypodermic needle, but no substance was injected. Handled Ss $(\mathrm{H})$ were treated in the same manner as other Ss, but were not injected.

At 70 days of age offspring of treated Ss were weighed and placed on a 23-hr. food deprivation schedule. On days $71-73$ Ss received a total of 20 training trials in a 3-ft. runway. On days 74-78 Ss received 24 trials in a Lashley type-III maze. During training and maze learning, on reaching the goal Ss were allowed to eat for $10 \mathrm{sec}$. The intertrial interval during maze learning was approximately $15 \mathrm{~min}$. Following the last maze learning trial Ss were weighed. Results and Discussion

Analysis of variance of 70 day weights indicated that males were heavier than females $(F=117.65, \mathrm{df}=$ $1 / 198, p<.001)$. No other weight differences were significant.

The maze learning criterion was that used by Werboff \& Kesner (1963) and Hoffeld \& Webster (1965), two out of three errorless trials, $20 \mathrm{sec}$. or less in duration. Analysis of variance of the criterion scores yielded only a significant interaction $(F=3.41, d f=$ $4 / 198, p<.05$ ) between treatments and stages of pregnancy. The Duncan Range Test showed that the interaction was due to the fact that in I and II there were 


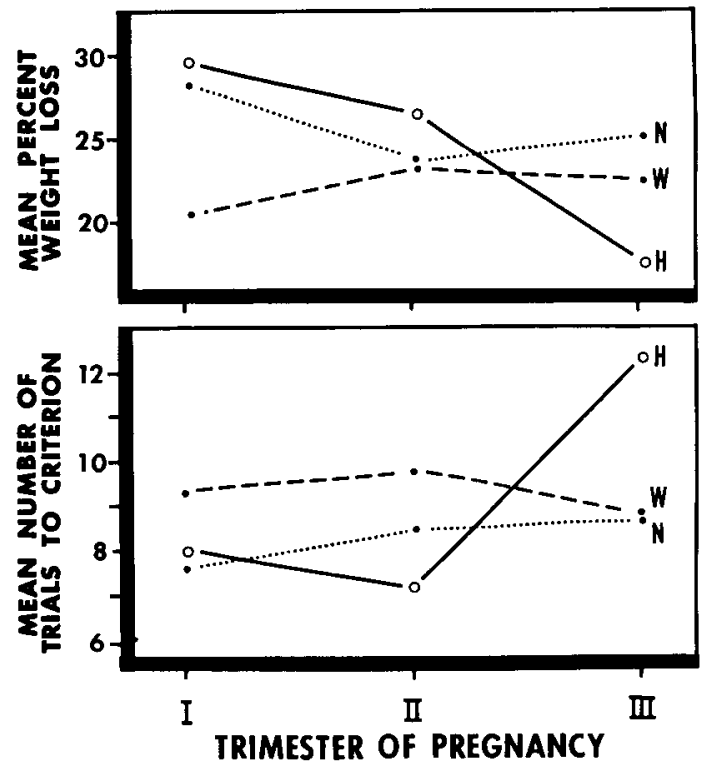

Fig. 1. Mean number of trials to the leaming criterion and mean percent weight loss shown as a function of treatment conditions and trimesters during which treatments were administered.

no significant differences among treatment groups, but in III H Ss took significantly longer $(p=.05)$ to reach criterion than the others (see Fig. 1).

An additional dependent variable measure was made in the present study that was not reported by Werboff and Kesner and Hoffeld and Webster. Analysis of variance of percent weight loss by Ss during the experiment showed several significant effects. Males lost significantly more weight than females $(F=13.56$, df $=1 / 198, p<.01)$. The treatment variable was significant $(F=11.94, d f=2 / 198, p<.01)$. A Duncan Range Test indicated that $W$ Ss lost a significantly smaller percentage of weight $(p<.05)$ than either $N$ or $H$ Ss. The stage of pregnancy effect was also significant $(F=18.84$, df $=2 / 198, p<.01)$. A Duncan Range Test showed that Ss treated in III lost significantly less weight $(p<.05)$ than Ss treated in II; and that Ss treated in II lost significantly less weight than Ss treated in 1 . The effects of injection procedures were shown as decreases in weight lost across successive trimesters of gestation.

The interaction between treatments and stages of pregnancy was significant $(F=19.07, d f=4 / 198, p<.01)$. A Duncan Range Test showed that in I W Ss lost significantly less weight than $\mathrm{N}$ or $\mathrm{H}$ Ss. In III H Ss lost significantly less weight than $\mathrm{N}$ or W Ss (see Fig. 1).

The dominant finding of this study lies in the interesting relationship that was revealed between maze performance and percent weight loss during the experiment. The relationship becomes apparent when Fig. 1 is examined. Weight loss was inversely related to maze performance. For the percent weight loss and trials to criterion scores of all Ss a Pearson $r=-.295$ $(p<.01)$. These findings lead to the conclusion that the 23-hr. deprivation procedures used in studies such as this one may bias learning data in favor of those Ss who are least resistant to conditions of food deprivation. A more appropriate procedure would be to reduce Ss to approximately $80 \%$ of their 70 day weights. Neither Werboff and Kesner nor Hoffeld and Webster gave data on weight losses. In future studies of this sort differences in the physical condition of experimental groups should be adequately ruled out before learning deficits are attributed to experimental manipulations.

Extensive comparisons between the present findings and the Hoffeld and Webster study seemed unwarranted. However, it should be observed that neither weight lo'ss nor maze learning scores for the $\mathrm{W}$ group in II diverged significantly from those of $\mathrm{W}$ groups in $\mathrm{I}$ and III. This result is not in accord with the results reported by Hoffeld and Webster.

\section{References}

Werboff, J., \& Kesner, R. Nature, 1963, 197, 106-107.

Hoffeld, D. R., \& Webster, R. L. Nature, 1965, 205, 1070-1072. Thompson, W. R., \& Goldenberg, L. Psychol. Rep., 1962, 10, 759 774.

\section{Note}

1. This research was supported by Wallace Laboratories, Cranbury, N. J., and by grant no. HD 02241-01 from the National Institute of Child Health and Human Development. I wish to acknowledge the assistance of Miss Susan A. Crandell in conducting this study. 